\section{Barrier Repair Therapy in Atopic Eczema: New Evidences in Improving Skin Functions with Topical Emolliency and Hydration Strategies}

\author{
Massimo Milani* \\ Medical Department Isdin, Via le Abruzzi 3, Milan, Italy
}

\section{Introduction}

Atopic Eczema (AE) is a very common chronic skin inflammatory disease characterized by flares and remission phases [1]. $\mathrm{AE}$ is the most common form of inflammatory skin diseases affecting up to $20 \%$ of children [2]. It is a typical disease of paediatric age with $90 \%$ of cases appearing before 5 years of age. However it could persist in adult age in 30\% of affected patients [3]. Recently Margolis et al., [4] have demonstrated that AE could actually continue in up to $80 \%$ of adult subjects who have suffered AE during childhood. This shows that AE should be considered a life-long illness. Skin xerosis and itch are the hallmark of the disease pointing out that skin barrier alteration is the background condition of AE [5]. From a clinical point of view $\mathrm{AE}$ is characterized by erythema, oedema, skin erosion and excoriation affecting mainly face, limbs and flexural areas [6]. In chronic phases lichenification is commonly seen [7]. AE has a profound impact in quality of life especially when skin conditions negatively affect sleep [8]. Alteration in skin barrier functions and an abnormal Th2-driven immune-response are the two pathogenetic mechanisms [9]. For several years the "Inside-Outside" dilemma has characterized the debate regarding which are the culprit mechanisms involved in the starting of the disease [10]. The pivotal works of Elias [11] and Cork [12] have definitely pointed out that skin barrier alteration is the "primum movens" defect causing the development of AE.

\section{Skin Barrier Alteration in Atopic Eczema}

A normal skin barrier function is crucial in order to maintain a correct hydration of the body and in order to block penetration

*Corresponding author: Massimo Milani, Medical Department Isdin, Via le Abruzzi 3, Milan, Italy, Tel: +39 0220520276; Fax: +39 0229411286; E-mail: massimo.milani@isdin.com

Citation: Milani M (2015) Barrier Repair Therapy in Atopic Eczema: New Evidences in Improving Skin Functions with Topical Emolliency and Hydration Strategies. J Clin Dermatol Ther 2: 011.

Received: May 08, 2015; Accepted: July 09, 2015; Published: July 23, 2015 through the skin of noxious substances such as toxins and allergens [13]. When skin barrier function is reduced, xerosis, alteration of skin microbioma with pathogenic bacteria colonization and inflammation occur [14]. It is now clearly demonstrated that $\mathrm{AE}$ is actually due to skin barrier alteration [15]. Furthermore, it is recognised that skin barrier dysfunction precedes eczema development. Three are the major skin barrier defects documented in subjects with AE: a reduced skin lipid contents [16] (mainly ceramide compartment), a reduced production of filaggrin [17] (both primary and acquired) and finally a reduced synthesis of skin-derived antimicrobial peptides [18]. Therefore AE could develop as a result of an increase allergens entry through an altered skin barrier and this in turn results in starting inflammatory processes mediated by a production of Th2-dependent pro-inflammatory cytokines [19]. A genetic defect in the production of filaggrin has been demonstrated in up to $40 \%$ of patients with $\mathrm{AE}[20]$. However in subjects with $\mathrm{AE}$ without a filaggrin genetic defects a reduced synthesis could be secondary to Th2-mediated responses. For example IL-25 could reduce filaggrin skin contents [21]. Also IL-17 is able to down-regulate filaggrin synthesis [22]. Lack or reduced skin level of filaggrin play a central role in altering the skin barrier function [23]. In fact normal amounts filaggrin are important in maintaining a correct skin hydration [24], and a correct $\mathrm{pH}$ [25]. When skin filaggrin levels are reduced there is a tendency of skin $\mathrm{pH}$ to increase [26]. This favours the activation of serin-protease enzymes which digest keratinocyte tight junctions further altering the barrier performances of the skin [27]. Filaggrin break-down products are pivotal in the formation of Natural Moisturizing Factor and in the acidification of epidermis. The skin barrier defect observed in atopic eczema therefore causes an increase in Transepidermal Water Loss (TEWL) favouring xerosis, an increase of allergen and irritants substances penetration provoking inflammation and a reduction of AMP production which could provoke an increase skin adhesion and proliferation of bacteria such as S.aureus which could initiate AE flare episodes [28]. As stated by Jung [29] dryness of the skin is a hallmark of AE. It is due to epidermal barrier as a consequence an increased TEWL. Therefore an altered skin barrier is the initial step which initiates a kind of "vicious circle" with dryness, tendency to itching and scratching, risk of super-infection and inflammation. In addition lipid compositions of Stratum Corneum (SC) could also play an important role in the pathogenesis of AE. Janssens et al., [30] quite recently have shown that in AE subjects both lesional and non lesional skin area present an altered lipid/protein ratio in comparison with normal controls. In addition the lipid/protein ratio alteration in SC of patients with AE correlated strongly with the skin barrier function and disease severity. The composition of lipid content for example with the increase of ceramides with an extreme short chain length is drastically increased in SC of AE patients. This alteration, independent from fillagrin mutations, leads to an aberrant lipid organization and a decreased skin barrier function [31]. However lipid content of SC could be also affected by inflammatory processes. Tawada et al., [32] have shown that cytokines, in particular Interferon gamma, could affect lipid synthesis in the skin compromising the barrier function of SC in AE subjects. These data are important 


\begin{tabular}{|c|c|c|c|c|c|}
\hline Author & Year & Product & Study Design & Subjects & Outcome \\
\hline Szczepanowska & 2008 & Topical corticosteroid vs. topical corticosteroid plus emollient & Randomised controlled & 52 & Improvement of EASI \\
\hline Patrizi & 2008 & Lipid-based Emollient cream & Randomised controlled & 60 & Improvement of Clinical assessment \\
\hline Belloni & & Lipid-based Emollient cream & Randomised controlled & 30 & Improvement of EASI score \\
\hline Marseglia & 2014 & Emollient/moisturizing plus Isoleucine cream & Randomised controlled & 107 & Improvement in EASI and Clinical evaluation \\
\hline
\end{tabular}

Table 1: Controlled Clinical Trials supporting the efficacy of emollient/moisturizing products in AE.

because suggest that alteration of lipid content of SC could be one of the direct causes of skin barrier alteration in $\mathrm{AE}$, but at the same time an alteration in lipid composition could be also a consequence of inflammatory processes during $\mathrm{AE}$.

\section{Skin Barrier Improvement: Rational and Evidence}

Emollient and moisturizing compounds are considered a main stay therapy of AE [33]. Several international guidelines point out that this strategy should be considered as a background approach for all grade of severity of AE. Daily use of an emollient is now universally recommended to enhance and protect skin barrier [34]. Conservative dry-skin care is very beneficial for AE and should form the basis of management of atopic eczema [35]. The National Institute for Health and Care Excellence (NICE) guidelines recommend the daily use of emollient and moisturizing for mild, moderate and severe AE [36]. The rational of the use of emollients in AE should be found mainly in the capability to correct the increased TEWL and therefore to reduce xerosis [37]. Restoring a normal skin hydration could have indirect positive effects also on $\mathrm{pH}$ and barrier function [38]. The skin barrier function improvement offered by emollient products is relevant in the long term strategy of $\mathrm{AE}$ treatment also because in quiescent atopic dermatitis the application of topical corticosteroid actually reduces skin barrier function with an increase in TEWL [39]. This underlies the importance of a daily care treatment of skin in this clinical setting. An ideal effective emollient product should be able to offer control to mild eczema, to reduce the use of topical steroid (the so called steroid sparing effect) and finally to prevent future eczema deterioration when use in between flares periods [40].

\section{Barrier Repair Therapy: How Improve Skin Barrier Functions}

Ceramide, filaggrin and Anti-Microbial-Peptides (AMP) defects are the three main mechanisms which characterize the skin barrier defect of AE [41]. Therefore an "ideal" emollient-moisturizing product should restore the lipid mantle, improve skin hydration and if possible to re-establish a normal AMP production. Pharmacological induction of AMPs at epithelial barriers could have therapeutic utility. It has been recently reported that the discovery of substances with low molecular weight can induce epithelial antimicrobial peptide production in cell-based assays. In particular L-isoleucine and its analogues are highly specific $B$-defensin inducers in epithelial cells. Fehlbaum et al., [42] have demonstrated that L-isoleucine, in a dose-dependent manner, could induce defensin production in epithelia. AMPs constitute an important component of the mammalian innate immune response [43]. Isoleucine therefore could be considered an AMP-promoter at skin level. Particular therapeutic interest in AE topical treatments is addressed to non-corticosteroid substances which could exert anti-inflammatory actions. Rhamnosoft is a biosaccaride formed by rhamnose, galactose and glucuronic acid. This compound is able to adhere to specific keratinocytes receptors. In keratinocytes in vitro cultures studies have shown that rhamnosoft could inhibit Interleukine 1 synthesis, inhibit neutrophil adhesion and reduce phospholipase 2 activity. In addition rhamnosoft stimulates beta-endorfin production [44]. This molecule therefore expresses anti-inflammatory action at skin level.

\section{Barrier Repair Therapy with Advanced Emollient Moisturizing Products: Clinical Data}

New emollient products available for patients with AE in general have a composition with different substances trying to address all the alterations of skin barrier (Table 1). In general there are lipid compounds such as ceramides and moisturizing substances such as glycerine. New available products could have additional non-corticosteroid substances with anti-inflammatory properties [38]. The clinical efficacy of emollient in AE has been supported by several clinical studies [45-47]. The multicentre Barrier Enhancement for Eczema Prevention (BEEP study) has shown that once-daily application of an emollient from birth through to the age of 6 months is able to prevent atopic dermatitis flares [48]. The 6-month cumulative incidence of eczema was $21.8 \%$ in the emollient group, in comparison with $43.3 \%$ in the control group. This means a $67 \%$ reduction in risk. In children with moderate AE, Szczepanowska et al., [49] have evaluated whether adding emollients to the standard topical corticosteroid therapy could influence the clinical outcome. Concomitant usage of emollients significantly improves xerosis and pruritus during corticosteroid treatment of atopic dermatitis, and enables to maintain clinical improvement after therapy discontinuation [50]. Therefore, dry-skin care is very beneficial for patients with $\mathrm{AE}$ reducing trans-epidermal water loss and reducing skin barrier compromise [51]. Patrizi et al., [52] in a multicentre randomised trial have shown that the use an emollient cream (MAS063DP) was effective in mild to moderate AE improving the clinical evolution. The same product was evaluated by Belloni et al., [53] in 30 adult subjects with AE, showing a reduction of EASI score after one month of therapy. In a recent multicentre trial conducted in 107 children with mild-moderate AE of the face, Marseglia et al., [54] have shown that a topical anti-inflammatory moisturising facial cream containing rhamnosoft, ceramides and L-Isoleucine was able to significantly reduce the Eczema Area Severity Index (EASI) score by $84 \%$ in comparison with baseline after 6 weeks of treatment (Figure 1). This clinical effect was statistically superior to the effect on EASI score obtained in the control group treated with a simple emollient cream. This clinical efficacy was confirmed in a cases series report of six children with moderate atopic dermatitis of the face [55]. A recent study conducted with a body cream containing rhamnosoft, ceramide, niacinamide and polidocanol and iso-leucine in 15 children with mild-to-moderate $\mathrm{AE}$ treated for 4 weeks has shown a $71 \%$ reduction of Eczema Severity score in comparison with baseline levels (Figure 2) [55]. The use of emollient products in newborn at high risk of development of $\mathrm{AE}$ could be useful also in preventing the appearance of the disease [56].

\section{Conclusion}

Every day's emollient treatment is considered a mainstay of AE treatment alone or in combination with other therapies. The use of 
Citation: Milani M (2015) Barrier Repair Therapy in Atopic Eczema: New Evidences in Improving Skin Functions with Topical Emolliency and Hydration Strategies. J Clin Dermatol Ther 2: 011.

Evolution of facial Eczema severity score

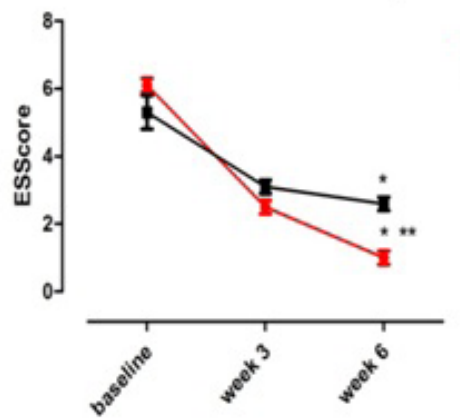

${ }^{*} \mathrm{P}<0.001$ vs baseline

" $\mathrm{P}>0.001$ vs control cream

Figure 1: Clinical efficacy of a ceramide, rhamnosoft and iso-leucine facial cream in $\mathrm{AE}$ in comparison with a standard emollient cream: Evolution of Eczema severity Score [54].

\section{Evolution of Eczema severity score}

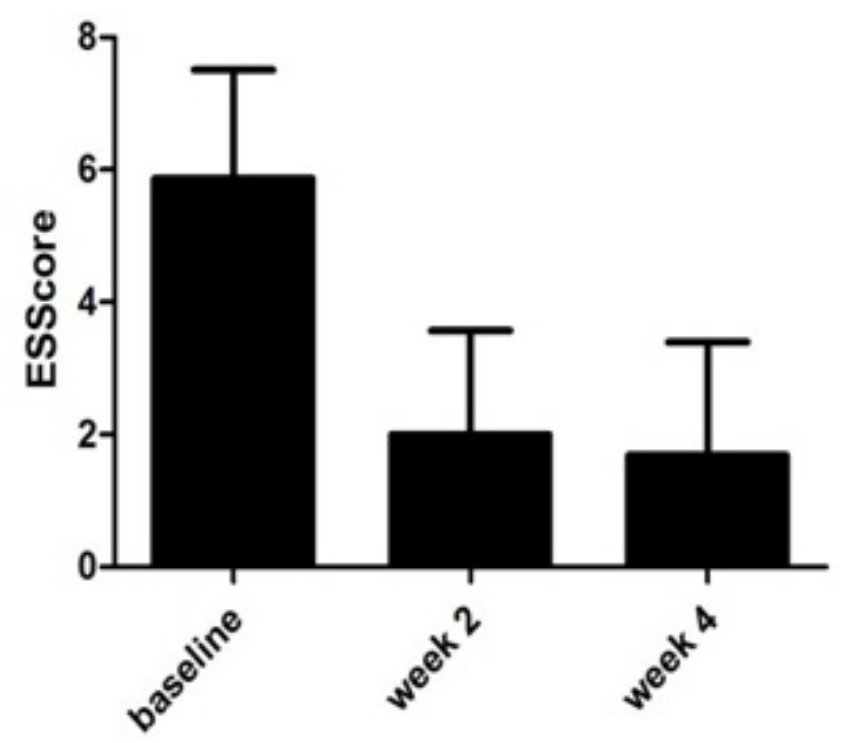

Figure 2: Clinical efficacy of a ceramide, niacinamide, iso-leucine body cream in AE: Evolution of Eczema severity Score [57].

emollients has shown to reduce the risk of $\mathrm{AE}$ flares and to reduce the need for topical corticosteroid. New emollient and moisturising products able to act on different aspects of skin barrier defects have demonstrated not only to control symptoms and signs of AE but also to improve the skin barrier functions acting specifically in the lipid component of skin barrier, in reducing inflammatory mechanisms and finally in normalising keratynocite AMP production.

\section{References}

1. Anonymous (1998) Worldwide variation in prevalence of symptoms of asthma, allergic rhinoconjunctivitis, and atopic eczema: ISAAC. The International Study of Asthma and Allergies in Childhood (ISAAC) Steering Committee. Lancet 351: 1225-1232.

2. Kay J, Gawkrodger DJ, Mortimer MJ, Jaron AG (1994) The prevalence of childhood atopic eczema in a general population. J Am Acad Dermatol 30: 35-39.
3. Williams HC, Strachan DP (1998) The natural history of childhood eczema: observations from the British 1958 birth cohort study. Br J Dermatol 139: 834-839.

4. Margolis JS, Abuabara K, Bilker W, Hoffstad O, Margolis DJ (2014) Persistence of mild to moderate atopic dermatitis. JAMA Dermatol 150: 593-600.

5. Elias PM (1983) Epidermal lipids, barrier function and desquamation. J Invest Dermatol 80: 44-49.

6. Archer CB (2000) The pathophysiology and clinical features of atopic dermatitis. In: Williams HC (ed.). Atopic dermatitis: The Epidemiology, Causes and Prevention of Atopic Eczema. Cambridge University Press, New York, USA. Pg no: 25-40.

7. Dotterud LK, Kvammen B, Lund E, Falk ES (1995) Prevalence and some clinical aspects of atopic dermatitis in the community of Sør-Varanger. Acta Derm Venereol 75: 50-53.

8. Kiebert G, Sorensen SV, Revicki D, Fagan SC, Doyle JJ, et al. (2002) Atopic dermatitis is associated with a decrement in health-related quality of life. Int J Dermatol 41: 151-158.

9. Kubo A, Nagao K, Amagai M (2012) Epidermal barrier dysfunction and cutaneous sensitization in atopic diseases. J Clin Invest 122: 440-447.

10. Leung DY, Jain N, Leo HL (2003) New concepts in the pathogenesis of atopic dermatitis. Curr Opin Immunol 15: 634-638.

11. Elias PM (1983) Epidermal lipids, barrier function, and desquamation. J Invest Dermatol 80: 44-49.

12. Cork MJ, Danby SG, Vasilopoulos Y, Hadgraft J, Lane ME, et al. (2009) Epidermal barrier dysfunction in atopic dermatitis. J Invest Dermatol 129: 1892 1908.

13. Steinert PM (2000) The complexity and redundancy of epithelial barrier function. J Cell Biol 151: 5-8.

14. Miedzobrodzki J, Kaszycki P, Bialecka A, Kasprowicz A (2002) Proteolytic activity of Staphylococcus aureus strains isolated from the colonized skin of patients with acute-phase atopic dermatitis. Eur $\mathrm{J}$ Clin Microbiol Infect Dis 21: $269-276$.

15. Hon KL, Wang SS, Leung TF (2012) The atopic march: from skin to the airways. Iran J Allergy Asthma Immunol 11: 73-77.

16. Sator PG, Schmidt JB, Hönigsmann H (2003) Comparison of epidermal hydration and skin surface lipids in healthy individuals and in patients with atopic dermatitis. J Am Acad Dermatol 48: 352-358.

17. Palmer CN, Irvine AD, Terron-Kwiatkowski A, Zhao $\mathrm{Y}$, Liao $\mathrm{H}$, et al. (2006) Common loss-of-function variants of the epidermal barrier protein filaggrin are a major predisposing factor for atopic dermatitis. Nat Genet 38: 441-446.

18. Kalinin AE, Kajava AV, Steinert PM (2002) Epithelial barrier function: assembly and structural features of the cornified cell envelope. Bioessays 24: 789800 .

19. Spergel JM, Mizoguchi E, Oettgen H, Bhan AK, Geha RS (1999) Roles of $\mathrm{TH} 1$ and $\mathrm{TH} 2$ cytokines in a murine model of allergic dermatitis. J Clin Invest 103: 1103-1111.

20. Sandilands A, O'Regan GM, Liao H, Zhao Y, Terron-Kwiatkowski A, et al. (2006) Prevalent and rare mutations in the gene encoding filaggrin cause ichthyosis vulgaris and predispose individuals to atopic dermatitis. J Invest Dermatol 126: 1770-1775.

21. Salimi M, Barlow JL, Saunders SP, Xue L, Gutowska-Owsiak D, et al. (2013) A role for IL-25 and IL-33-driven type- 2 innate lymphoid cells in atopic dermatitis. J Exp Med 210: 2939-2950.

22. Gutowska-Owsiak D, Schaupp AL, Salimi M, Selvakumar TA, McPherson T, et al. (2012) IL-17 downregulates filaggrin and affects keratinocyte expression of genes associated with cellular adhesion. Exp Dermatol 21: 104-110. 
Citation: Milani M (2015) Barrier Repair Therapy in Atopic Eczema: New Evidences in Improving Skin Functions with Topical Emolliency and Hydration Strategies. J Clin Dermatol Ther 2: 011.

23. Enomoto H, Hirata K, Otsuka K, Kawai T, Takahashi T, et al. (2008) Filaggrin null mutations are associated with atopic dermatitis and elevated levels of $\mathrm{IgE}$ in the Japanese population: a family and case-control study. J Hum Genet 53: 615-621.

24. Kezic S, Kemperman PM, Koster ES, de Jongh CM, Thio HB, et al. (2008) Loss-of-function mutations in the filaggrin gene lead to reduced level of natural moisturizing factor in the stratum corneum. J Invest Dermatol 128: 21172119.

25. Brown SJ, McLean WH (2012) One remarkable molecule: filaggrin. J Invest Dermatol 132: 751-762.

26. Jung M, Choi J, Lee SA, Kim H, Hwang J, et al. (2014) Pyrrolidone carboxylic acid levels or caspase-14 expression in the corneocytes of lesional skin correlates with clinical severity, skin barrier function and lesional inflammation in atopic dermatitis. J Dermatol Sci 76: 231-239.

27. Agrawal R, Woodfolk JA (2014) Skin barrier defects in atopic dermatitis. Curr Allergy Asthma Rep 14: 433.

28. Rippke F, Schreiner V, Doering T, Maibach HI (2004) Stratum corneum pH in atopic dermatitis: impact on skin barrier function and colonization with Staphylococcus aureus. Am J Clin Dermatol 5: 217-223.

29. Jung T, Stingl G (2008) Atopic dermatitis: therapeutic concepts evolving from new pathophysiologic insights. J Allergy Clin Immunol 122: 1074-1081.

30. Janssens M, van Smeden J, Puppels GJ, Lavrijsen AP, Caspers PJ, et al. (2014) Lipid to protein ratio plays an important role in the skin barrier function in patients with atopic eczema. Br J Dermatol 170: 1248-1255.

31. Janssens M, van Smeden J, Gooris GS, Bras W, Portale G, et al. (2012) Increase in short-chain ceramides correlates with an altered lipid organization and decreased barrier function in atopic eczema patients. J Lipid Res 53 : 2755-2766.

32. Tawada C, Kanoh H, Nakamura M, Mizutani Y, Fujisawa T, et al. (2014) Interferon- $y$ decreases ceramides with long-chain fatty acids: possible involvement in atopic dermatitis and psoriasis. J Invest Dermatol 134: 712-718.

33. Akdis CA, Akdis M, Bieber T, Bindslev-Jensen C, Boguniewicz M, et al (2006) Diagnosis and treatment of atopic dermatitis in children and adults: European Academy of Allergology and Clinical Immunology/American Academy of Allergy, Asthma and Immunology/PRACTALL Consensus Report. Allergy 61: 969-987.

34. Vestergaard C, Deleuran M (2014) Advances in the diagnosis and therapeutic management of atopic dermatitis. Drugs 74: 757-769.

35. Chamlin SL, Kao J, Frieden IJ, Sheu MY, Fowler AJ, et al. (2002) Ceramide-dominant barrier repair lipids alleviate childhood atopic dermatitis: changes in barrier function provide a sensitive indicator of disease activity. $J$ Am Acad Dermatol 47: 198-208.

36. Lewis-Jones S, Mugglestone MA, Guideline Development Group (2007) Management of atopic eczema in children aged up to 12 years: summary of NICE guidance. BMJ 335: 1263-1264.

37. Hon KL, Leung AK (2013) Use of ceramides and related products for childhood-onset eczema. Recent Pat Inflamm Allergy Drug Discov 7: 12-19.

38. Cork MJ, Danby S (2009) Skin barrier breakdown: a renaissance in emollient therapy. Br J Nurs 18: 872, 874, 876-877.

39. Kao JS, Fluhr JW, Man MQ, Fowler AJ, Hachem JP, et al. (2003) Short-term glucocorticoid treatment compromises both permeability barrier homeostasis and stratum corneum integrity: inhibition of epidermal lipid synthesis accounts for functional abnormalities. J Invest Dermatol 120: 456-464.
40. Hon KL, Wang SS, Pong NH, Leung TF (2013) The ideal moisturizer: a survey of parental expectations and practice in childhood-onset eczema. J Dermatolog Treat 24: 7-12.

41. Leung DY, Jain N, Leo HL (2003) New concepts in the pathogenesis of atopic dermatitis. Curr Opin Immunol 15: 634-638.

42. Fehlbaum P, Rao M, Zasloff M, Anderson GM (2000) An essential amino acid induces epithelial beta -defensin expression. Proc Natl Acad Sci USA 97: $12723-12728$

43. Rivas-Santiago CE, Hernández-Pando R, Rivas-Santiago B (2013) Immunotherapy for pulmonary TB: antimicrobial peptides and their inducers. Immunotherapy 5: 1117-1126.

44. Andrès E, Molinari J, Péterszegi G, Mariko B, Ruszova E, et al. (2006) Pharmacological properties of rhamnose-rich polysaccharides, potential interest in age-dependent alterations of connectives tissues. Pathol Biol (Paris) 54: 420-425.

45. Hon KL, Leung AK, Barankin B (2013) Barrier repair therapy in atopic dermatitis: an overview. Am J Clin Dermatol 14: 389-399.

46. Weber TM, Samarin F, Babcock MJ, Filbry A, Rippke F (2015) Steroid-Free Over-the-Counter Eczema Skin Care Formulations Reduce Risk of Flare, Prolong Time to Flare, and Reduce Eczema Symptoms in Pediatric Subjects With Atopic Dermatitis. J Drugs Dermatol 14: 478-485.

47. Gayraud F, Sayag M, Jourdan E (2015) Efficacy and tolerance assessment of a new type of dermocosmetic in infants and children with moderate atopic dermatitis. J Cosmet Dermatol 14: 107-112.

48. Centre of Evidence-Based Dermatology (2014) Barrier Enhancement Eczema Prevention (The BEEP Study). The University of Nottingham, England, UK.

49. Szczepanowska J, Reich A, Szepietowski JC (2008) Emollients improve treatment results with topical corticosteroids in childhood atopic dermatitis: a randomized comparative study. Pediatr Allergy Immunol 19: 614-618.

50. Simpson E, Böhling A, Bielfeldt S, Bosc C, Kerrouche N (2013) Improvement of skin barrier function in atopic dermatitis patients with a new moisturizer containing a ceramide precursor. J Dermatolog Treat 24: 122-125.

51. Tarr A, Iheanacho I (2009) Should we use bath emollients for atopic eczema? BMJ 339: 4273 .

52. Patrizi A, Capitanio B, Neri I, Giacomini F, Sinagra JL, et al. (2008) A double-blind, randomized, vehicle-controlled clinical study to evaluate the efficacy and safety of MAS063DP (ATOPICLAIR) in the management of atopic dermatitis in paediatric patients. Pediatr Allergy Immunol 19: 619-625.

53. Belloni G, Pinelli S, Veraldi S (2005) A randomised, double-blind, vehicle-controlled study to evaluate the efficacy and safety of MAS063D (Atopiclair) in the treatment of mild to moderate atopic dermatitis. Eur J Dermatol 15: 31-36.

54. Marseglia A, Licari A, Agostinis F, Barcella A, Bonamonte D, et al. (2014) Local rhamnosoft, ceramides and L-isoleucine in atopic eczema: a randomized, placebo controlled trial. Pediatr Allergy Immunol 25: 271-275.

55. Puviani M, Agostinis F, Milani M (2014) Barrier repair therapy for facial atopic eczema with a non-steroidal emollient cream containing rhamnosoft, ceramides and iso-leucine. A six-case report series. Minerva Pediatr 66: 307-311.

56. Simpson EL, Chalmers JR, Hanifin JM, Thomas KS, Cork MJ, et al. (2014) Emollient enhancement of the skin barrier from birth offers effective atopic dermatitis prevention. J Allergy Clin Immunol 134: 818-823.

57. Agostinis F, Milani M (2015) Barrier Repair Therapy in Atopic Eczema: Efficacy of an isoleucine, rhamnosoft and niacinamide body cream. Accepted Poster at 24 ${ }^{\text {th }}$ EADV Congress-October 2015, Copenhagen, Denmark. 